\title{
The degree of labor pain at the time of epidural analgesia in nulliparous women influences the obstetric outcome
}

\author{
Jae Hee Woo, Jong Hak Kim, Guie Yong Lee, Hee Jung Baik, Youn Jin Kim, \\ Rack Kyung Chung, Du Gyun Yun, and Chae Hwang Lim \\ Department of Anesthesiology and Pain Medicine, Ewha Womans University School of Medicine, Seoul, Korea
}

\begin{abstract}
Background: The increased pain at the latent phase can be associated with dysfunctional labor as well as increases in cesarean delivery frequency. We aimed to research the effect of the degree of pain at the time of epidural analgesia on the entire labor process including the mode of delivery.

Methods: We performed epidural analgesia to 102 nulliparous women on patients' request. We divided the group into three based on NRS (numeric rating scale) at the moment of epidural analgesia; mild pain, NRS 1-4; moderate pain, NRS 5-7; severe pain, NRS 8-10. The primary outcome was the mode of delivery (normal labor or cesarean delivery).

Results: There were significant differences in the mode of delivery among groups. Patients with severe labor pain had a significantly higher cesarean delivery compared to patients with moderate labor pain $(\mathrm{P}=0.006)$. The duration of the first and second stage of labor, fetal heart rate, use of oxytocin and premature rupture of membranes had no differences in the three groups.

Conclusions: Our research showed that the degree of pain at the time of epidural analgesia request might influence the rate of cesarean delivery. Further research would be necessary for clarifying the mechanism that the augmentation of pain affects the mode of delivery.
\end{abstract}

Key Words: Epidural analgesia, Labor pain, Obstetric delivery.

\section{Introduction}

The degree of pain during labor progress has been suggested to be associated with prolonged labor or the frequency of the ce-

Corresponding author: Jong Hak Kim, M.D., Ph.D.

Department of Anesthesiology and Pain Medicine, Ewha Womans University School of Medicine, 1071, Anyangcheon-ro, Yangcheon-gu, Seoul 158-710, Korea

Tel: 82-2-2650-5089, Fax: 82-2-2655-2924

E-mail: kjhanes@ewha.ac.kr

Received: January 7, 2015.

Revised: February 25, 2015.

Accepted: March 15, 2015.

Korean J Anesthesiol 2015 June 68(3): 249-253

http://dx.doi.org/10.4097/kjae.2015.68.3.249 sarean delivery [1-3]. Labor pain differs greatly from individual's physical and mental condition and became severe as uterine cervical dilation increases while labor progresses. Several studies reported an association between obstetric outcome and pain score in relatively advanced labor $[1,3]$, whereas two previous reports have suggested that the degree of pain at the time of epidural analgesia can influence the obstetric result. In 1989, Wuitchik et al. [2] demonstrated that pain in the latent phase was predictive of mode of delivery and duration of labor, however, they did not provide any information about analgesic method including epidural analgesia. On the contrary, Beilin et al. [4] did not found an association between the labor pain at the time of epidural analgesia and mode of delivery in their retrospective study. Many variables including the timing of epidural analgesia and pain assessment method were not controlled that could affect their results.

(c) This is an open-access article distributed under the terms of the Creative Commons Attribution Non-Commercial License (http://creativecommons.org/ licenses/by-nc/4.0/), which permits unrestricted non-commercial use, distribution, and reproduction in any medium, provided the original work is properly cited. 
In this prospective research, we investigated the effect of the severity of labor pain at the time of epidural analgesia on the mode of delivery in nulliparous women. We hypothesized that labor pain at the time of epidural analgesia would be associated with the entire labor process including the mode of delivery.

\section{Materials and Methods}

This study was approved by the Hospital Ethics Committee at our institution and written informed consent was obtained from all women. The American Society of Anesthesiologists physical status I-II nulliparous women who requested epidural analgesia during working hours were enrolled from January to December 2013. The inclusion criteria were singleton pregnancies, gestational ages of 35-41 weeks, cervical dilatation of less than $4 \mathrm{~cm}$ and vertex fetal presentations. We considered a cervical dilatation under $4 \mathrm{~cm}$ to indicate latent phase of labor. The women who had pregnancy complications, contraindication of epidural analgesia or fetal abnormality were excluded.

The epidural analgesia was done when the patients requested epidural analgesia for pain relief. The patient's pulse, blood pressure, oxygen saturation, fetal heart rate and the cervical dilatation were checked before the procedure. The pain was evaluated with numeric rating scale (NRS; 0 , no pain to 10 , unimaginable pain) at the time of epidural analgesia. Based on this NRS scores, the patients were divided into three groups; $1-4$ for mild pain, 5-7 for moderate pain, and 8-10 for severe pain.

Before epidural analgesia, we injected $500-1,000 \mathrm{ml}$ of lactated Ringer's solution. The patient was placed in the right lateral decubitus position. A 17-gauge Tuohy needle was inserted towards the epidural space with the loss of air resistance method at the lumbar spine between L2-L5. We inserted a catheter into the epidural space and brought the catheter tip above $4 \mathrm{~cm}$ from the insertion level. We injected $3 \mathrm{ml}$ of chirocaine $0.375 \%$ including a concentration of $1: 200,000$ epinephrine as a test dose. The patient was turned to a supine position with a wedge beneath the right side for left uterine displacement. After confirming no sign of subarachnoid injection and blood vessel injection, $10 \mathrm{ml}$ of ropivacaine $0.15 \%$ including fentanyl $50 \mu \mathrm{g}$ was injected as a loading dose. This was followed by a continuous epidural infusion of ropivacaine $0.1 \%$ and fentanyl $(1.5 \mu \mathrm{g} / \mathrm{ml})$ at a speed of $10 \mathrm{ml} / \mathrm{h}$ through the machine (AC 110, Ambix, Ehwa Medical, Seoul, Korea).

After the procedure, blood pressure, pulse of the patients and fetal heart rate were recorded. Sensory blockade level by using alcohol cotton and pain score by NRS were assessed 30 minutes after injection of loading dose. The first stage of labor was defined as the time from the moment performing epidural analgesia to the instant when the cervix dilated about $10 \mathrm{~cm}$. The second stage of labor was defined as the time from $10 \mathrm{~cm}$ dilated cervix to delivery. The primary outcome was the mode of delivery; spontaneous vaginal delivery or cesarean delivery. The duration of the first and second stage of labor, usage of oxytocin, amniorhexis, fetal weight at the time of delivery and Apgar score were recorded.

\section{Statistical analysis}

SPSS (ver. 18.0, Chicago, IL, USA) was used for the statistical analysis. Data are presented as mean \pm standard deviation (SD) or median with interquartile range (IQR) as appropriate. The Kolmogorov-Smirnov test was used to test for normality of the distribution. Continuous variables were analyzed by ANOVA or Kruskal-Wallis test after assessment for normality. Discrete variables were analyzed using chi-square test. Then, a Bonferroni correction was applied for three comparisons between groups and adjusted $\mathrm{P}$ value $(\mathrm{P}<0.05 / 3=0.017)$ was considered statistically significant. Otherwise, $\mathrm{P}$ values of less than 0.05 were considered statistically significant.

\section{Results}

During the period of the study, 102 nulliparous women received epidural analgesia during working hours. Of these, 16,

Table 1. Maternal Characteristics

\begin{tabular}{|c|c|c|c|}
\hline & $\begin{array}{l}\text { Mild pain } \\
(\mathrm{n}=16)\end{array}$ & $\begin{array}{l}\text { Moderate pain } \\
\quad(\mathrm{n}=44)\end{array}$ & $\begin{array}{l}\text { Severe pain } \\
\quad(\mathrm{n}=42)\end{array}$ \\
\hline Age (yr) & $30.4 \pm 3.8$ & $31.5 \pm 4.0$ & $31.1 \pm 3.4$ \\
\hline Body weight $(\mathrm{kg})$ & $67.6 \pm 6.6$ & $65.7 \pm 8.6$ & $66.3 \pm 8.2$ \\
\hline Height $(\mathrm{cm})$ & $162.8 \pm 4.0$ & $158.08 \pm 5.0$ & $161.3 \pm 4.3$ \\
\hline Gestational age (week) & $39.1 \pm 1.5$ & $39.3 \pm 1.2$ & $39.1 \pm 1.3$ \\
\hline Cervix dilatation at the time of epidural analgesia $(\mathrm{cm})$ & $3.0 \pm 0.6$ & $2.8 \pm 0.6$ & $2.9 \pm 0.7$ \\
\hline NRS at the time of epidural analgesia request ${ }^{\ddagger}$ & $3(3-4)$ & $6(5-7)^{*}$ & $8(8-10)^{*}$ \\
\hline NRS after loading dose $e^{\S}$ & $0(0-1)^{\dagger}$ & $0(0-2)^{\dagger}$ & $1(0-3)^{*, \dagger}$ \\
\hline Sensory level after loading dose ${ }^{\S}$ & Т $9(7-10)$ & Т $9(8-10)$ & Т $9(6-10)$ \\
\hline
\end{tabular}

Values are mean $\pm \mathrm{SD}$ or median (interquartile range). NRS: numeric rating scale. ${ }^{*} \mathrm{P}<0.05$ compared to patients with mild pain, ${ }^{\dagger} \mathrm{P}<0.05$ compared to NRS before loading dose. ${ }^{\ddagger}$ At the time when the patient requested epidural analgesia at their latent phase. ${ }^{\S} 30$ minutes after injection of loading dose. 
44 and 42 women had the mild, moderate and severe pain at the time of epidural analgesia, respectively. There were no differences in age, height, weight, gestational age and the degree of cervical dilatation at the time of epidural analgesia in the three groups. Thirty minutes after epidural injection of the loading dose, satisfactory sensory blockade and significant pain relief was achieved in all groups although there was a statistical difference in NRS among groups (Table 1). The parturient women's blood pressure, pulse and fetal heart beats before and after epidural analgesia showed no differences, and none of the patients had any abnormal findings such as hypotension or bradyarrhythmia (Table 2).

There were significant differences in the mode of delivery among the three groups ( $\mathrm{P}=0.018) ; 5$ of 16 patients, 4 of 44 patients and 14 of 42 patients in the low, moderate and severe pain group, respectively (Fig. 1). The patients with severe labor pain had a significantly higher cesarean delivery compared with moderate pain group $(\mathrm{P}<0.017)$ but revealed no significant difference in the mode of delivery when compared with mild pain groups $(\mathrm{P}>0.017)$. Cesarean delivery was performed at the discretion of the obstetrician, as indicated. In patients with mild pain, two were performed for fetal distress and three for dystocia. In patients with moderate pain, three had cesarean delivery for fetal distress and one for dystocia. In patients with severe pain, eight had cesarean delivery for fetal distress and six for dystocia. The other parameters such as oxytocin usage, premature rupture of membranes and duration of the first and second stage of labor had no differences among the three

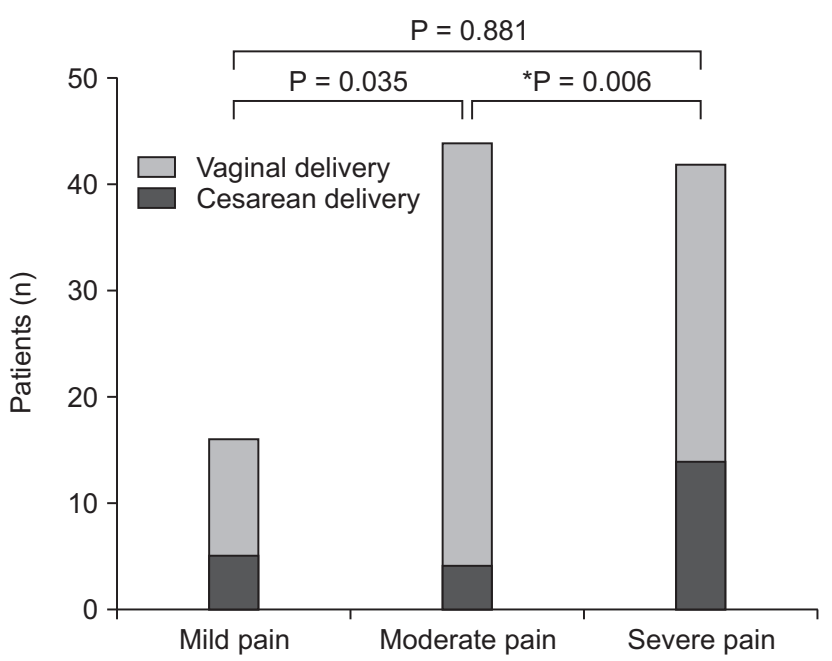

Fig. 1. The mode of delivery. $* \mathrm{P}$ value less than $0.05 / 3(0.017)$ was considered statistically significant.

Table 2. Maternal BP, HR and FHR before and after Epidural Analgesia

\begin{tabular}{|c|c|c|c|c|}
\hline & $\begin{array}{l}\text { Mild pain } \\
(\mathrm{n}=16)\end{array}$ & $\begin{array}{l}\text { Moderate pain } \\
\quad(\mathrm{n}=44)\end{array}$ & $\begin{array}{l}\text { Severe pain } \\
\quad(\mathrm{n}=42)\end{array}$ & $\mathrm{P}$ value \\
\hline \multicolumn{5}{|l|}{ Before epidural analgesia } \\
\hline Systolic BP (mmHg) & $119.1 \pm 9.5$ & $122.8 \pm 14.4$ & $128.0 \pm 17.2$ & 0.09 \\
\hline Diastolic BP (mmHg) & $69.6 \pm 10.4$ & $72.1 \pm 11.2$ & $76.0 \pm 14.5$ & 0.15 \\
\hline HR (beats/min) & $70.7 \pm 10.7$ & $73.7 \pm 7.3$ & $75.2 \pm 12.2$ & 0.32 \\
\hline FHR (beats/min) & $140.3 \pm 8.9$ & $137.4 \pm 8.1$ & $137.8 \pm 8.9$ & 0.51 \\
\hline \multicolumn{5}{|c|}{ After injection of loading dose } \\
\hline Systolic BP (mmHg) & $111.6 \pm 8.0$ & $114.8 \pm 10.6$ & $117.1 \pm 14.0$ & 0.31 \\
\hline Diastolic BP (mmHg) & $64.5 \pm 9.9$ & $68.6 \pm 8.8$ & $70.4 \pm 11.0$ & 0.17 \\
\hline HR (beats/min) & $67.0 \pm 6.1$ & $71.2 \pm 7.5$ & $71.5 \pm 11.5$ & 0.29 \\
\hline FHR (beats/min) & $136.5 \pm 7.9$ & $137.9 \pm 8.9$ & $136.5 \pm 9.8$ & 0.76 \\
\hline
\end{tabular}

Values are mean \pm SD. BP: blood pressure, HR: heart rate, FHR: fetal heart rate.

Table 3. Labor Characteristics and Mode of Delivery

\begin{tabular}{|c|c|c|c|c|}
\hline & $\begin{array}{l}\text { Mild pain } \\
(\mathrm{n}=16)\end{array}$ & $\begin{array}{l}\text { Moderate pain } \\
\quad(\mathrm{n}=44)\end{array}$ & $\begin{array}{l}\text { Severe pain } \\
\quad(\mathrm{n}=42)\end{array}$ & $P$ value \\
\hline Oxytocin use & 11 & 29 & 26 & 0.86 \\
\hline Membrane rupture & 5 & 11 & 10 & 0.84 \\
\hline Duration of first stage I (h) & $8.6 \pm 6.0$ & $9.8 \pm 7.0$ & $10.4 \pm 4.8$ & 0.72 \\
\hline Duration of second stage II (h) & $0.7 \pm 0.4$ & $1.0 \pm 0.7$ & $1.0 \pm 0.7$ & 0.42 \\
\hline Mode of delivery & & & & 0.02 \\
\hline Vaginal delivery & $11(68.75 \%)$ & 40 (90.9\%) & $28(66.67 \%)$ & \\
\hline Cesarean delivery & $5(31.25 \%)$ & $4(9.09 \%)$ & $14(33.33 \%) *$ & \\
\hline
\end{tabular}

Values are mean $\pm \mathrm{SD}$ or number of patients (percentage). $* \mathrm{P}<0.05 / 3(0.017)$ compared to patients with moderate pain. 
Table 4. Neonatal Outcome

\begin{tabular}{lcccc}
\hline & $\begin{array}{c}\text { Mild pain } \\
(\mathrm{n}=16)\end{array}$ & $\begin{array}{c}\text { Moderate pain } \\
(\mathrm{n}=44)\end{array}$ & $\begin{array}{c}\text { Severe pain } \\
(\mathrm{n}=42)\end{array}$ & P value \\
\hline Birth weight & $3.38 \pm 0.33$ & $3.23 \pm 0.45$ & $3.29 \pm 0.51$ & 0.51 \\
APGAR -1 min & $9.3 \pm 1.0$ & $9.6 \pm 0.8$ & $9.4 \pm 0.8$ & $(7-10)$ \\
& $(7-10)$ & $(7-10)$ & $10.0 \pm 0.2$ & 0.30 \\
APGAR -5 min & $9.8 \pm 0.6$ & $9.8 \pm 1.4$ & $(9-10)$ \\
\hline
\end{tabular}

Values are mean \pm SD (range).

groups (Table 3). Neonatal outcome, weight or Apgar score at 1 or 5 minute showed no differences either. There was no newborn baby whose Apgar score was under 7 (Table 4). Our results achieved a power of 0.99 and an $\alpha$ of 0.05 . (chi-square test).

\section{Discussion}

We investigated whether the degree of labor pain at the time of epidural analgesia, latent phase of labor, affected labor progress in nulliparous women who underwent epidural anesthesia. We found that the degree of labor pain in the latent phase was associated with the mode of delivery. The cesarean delivery rates were higher in the group experiencing severe pain (33.33\%) than in the group experiencing moderate pain (9.09\%). The degree of labor pain at the time of epidural analgesia was not related to the duration of the first and second stage of labor. The present study minimized bias against the impact of epidural analgesia on the cesarean delivery by conducting a prospective study by standardization of patient management such as analgesic methods. Moreover, previous lots of studies used indirect studies that evaluated pain by the number of requests for an additional analgesics [1-3,5-12], while this study divided into groups on the basis of only initial pain. There was also no difference among three groups in maternal, fetal and obstetric factors that could have an impact on labor pain and dystocia.

There has been an ongoing debate about the issue that epidural analgesia during labor can increase cesarean delivery rates. Some authors demonstrated that epidural analgesia could increase the rate of forceps and cesarean delivery $[5,6,13,14]$. However, most recent studies show that epidural analgesia using a low concentration of local anesthetic and narcotics do not increase cesarean delivery rates while it can extend labor times [7-11]. The increased rate of cesarean delivery in individuals who received epidural analgesia can be explained by various factors such as mother or fetus' factors, not by a direct relationship with epidural analgesia. Among them, labor pain is one of the factors to relate with the obstetric outcome and can be a confounding factor when interpreting effects of epidural analgesia on labor outcome $[1-3,6,12]$.

The target groups in this study were divided into three groups using a NRS on the basis of previous studies [4,15-17]. Usually the pain of the NRS $1-4$ belongs to mild pain with a minimal impact of pain and NRS 5-6 indicated moderate pain with a greater impact on the functioning. The pain of the NRS 7 or higher indicated a severe pain with the greatest impact on the functioning [15]. According to measurement using a visual analog scale by Collins et al. [16], moderate pain and severe pain were the average 49 and 75, respectively. Also, Wallenstein et al. [17] showed that the average VAS score of moderate pain and severe pain were 50 and 80 , respectively.

The frequency of receiving the cesarean delivery due to dystocia among pregnant women who received epidural analgesia was vary from 5 to $25 \%$, which indicated that other various factors were involved beside epidural analgesia itself [1-3,6,12]. The labor progress is very complex and dystocia can be induced by various causes such as a fetus size, fetal presentation, the anatomy of the pelvic, a uterine malformation, maternal age, use of oxytocin, and uterine activity.

It was highlighted that the pain and cognitive activity in the latent phase, not in the active phase, were a prognostic of obstetric outcome of labor progress [2], which was consistent with our results. Those authors reported that patients who complained of severe pain in their latent phase showed prolonged labor time, increased frequency of dystocia and surgical labor rates, when compared with the patients who had less pain. On the other hand, Beilin et al. [4] presented their retrospective results that nulliparous women showed no difference cesarean delivery rates regardless of labor pain at the time of epidural placement. However, this retrospective study included more patients experiencing pre-diagnosed dystocia than other studies, which led to much higher cesarean delivery rates in all groups.

Little has been known about the mechanism that the augmentation of pain increases dystocia. Severe pain in the latent phase could increase the levels of catecholamine and cortisol and reduce uterine activity $[2,18]$. Our results showed that cesarean delivery frequency in patients with severe pain was significantly higher than that in patients with moderate pain. However, there was no difference between mild and severe pain group. We considered these results for two reasons. First, the number of patients with mild pain was less than other groups. Second, there is 
a possibility that the epidural analgesia was too early conducted because it was performed on the patients' request. There is a controversy over whether the time of epidural analgesia is a factor that can affect labor outcome, although most recent studies have concluded that early placement of epidural analgesia do not increase the cesarean delivery rates $[9,19]$. Holmes et al. [20] reported that women who present to hospital at $0-3 \mathrm{~cm}$ of cervical dilatation have a higher risk of caesarean delivery regardless of epidural analgesia.

There were some limitations of this study. First, a few patients relatively participated in this study. This was because that the overall delivery rates have been declined, and only nulliparous women with fetuses in vertex presentation were selected. The criteria of cervical dilation was determined up to $4 \mathrm{~cm}$, and overnight deliveries were excluded. Second, as patients were allowed to choose the time of epidural analgesia on their request, the measurement of the NRS at the moment of epidural analgesia might be affected. Third, supplemental boluses except for a constant epidural continuous infusion were not administered dur- ing the labor progress.

In conclusion, the pain score at the time of epidural analgesia might affect the methods of delivery. The severe pain at the latent phase should be considered not as the low pain thresholds of patients simply but as a marker of intrinsically difficult labor and more careful management would be needed. Also, the labor pain at latent phase can play a role of potential confounding factor in the study regarding an association between the epidural analgesia and the cesarean delivery rate. As labor progress is influenced by complex factors, further studies will be needed in order to find out the mechanism that the augmentation of pain increases dystocia.

\section{ORCID}

Jae Hee Woo, http://orcid.org/0000-0002-1993-1687

Hee Jung Baik, http://orcid.org/0000-0002-8877-0274

Youn Jin Kim, http://orcid.org/0000-0001-9189-5839

\section{References}

1. Panni MK, Segal S. Local anesthetic requirements are greater in dystocia than in normal labor. Anesthesiology 2003; 98: 957-63.

2. Wuitchik M, Bakal D, Lipshitz J. The clinical significance of pain and cognitive activity in latent labor. Obstet Gynecol 1989; 73: 35-42.

3. Hess PE, Pratt SD, Soni AK, Sarna MC, Oriol NE. An association between severe labor pain and cesarean delivery. Anesth Analg 2000; 90: 881-6.

4. Beilin Y, Mungall D, Hossain S, Bodian CA. Labor pain at the time of epidural analgesia and mode of delivery in nulliparous women presenting for an induction of labor. Obstet Gynecol 2009; 114: 764-9.

5. Alexander JM, Lucas MJ, Ramin SM, McIntire DD, Leveno KJ. The course of labor with and without epidural analgesia. Am J Obstet Gynecol 1998; 178: 516-20.

6. Debiec J, Conell-Price J, Evansmith J, Shafer SL, Flood P. Mathematical modeling of the pain and progress of the first stage of nulliparous labor. Anesthesiology 2009; 111: 1093-110.

7. Indraccolo U, Ripanelli A, Di Iorio R, Indraccolo SR. Effect of epidural analgesia on labor times and mode of delivery: a prospective study. Clin Exp Obstet Gynecol 2012; 39: 310-3.

8. Cheek TG, McGonigal ET. Epidural anesthesia and the progress of labor. Curr Opin Anaesthesiol 1998; 11: 265-9.

9. Halpern SH, Abdallah FW. Effect of labor analgesia on labor outcome. Curr Opin Anaesthesiol 2010; 23: 317-22.

10. Decca L, Daldoss C, Fratelli N, Lojacono A, Slompo M, Stegher C, et al. Labor course and delivery in epidural analgesia: a case-control study. J Matern Fetal Neonatal Med 2004; 16: 115-8.

11. Kukulu K, Demirok H. Effects of epidural anesthesia on labor progress. Pain Manag Nurs 2008; 9: 10-6.

12. Segal S, Blatman R, Doble M, Datta S. The influence of the obstetrician in the relationship between epidural analgesia and cesarean section for dystocia. Anesthesiology 1999; 91: 90-6.

13. Lieberman E, Lang JM, Cohen A, D’Agostino R Jr, Datta S, Frigoletto FD Jr. Association of epidural analgesia with cesarean delivery in nulliparas. Obstet Gynecol 1996; 88: 993-1000.

14. Mayberry LJ, Clemmens D, De A. Epidural analgesia side effects, co-interventions, and care of women during childbirth: a systematic review. Am J Obstet Gynecol 2002; 186(5 Suppl Nature): S81-93.

15. Alexander JM, Sharma SK, McIntire DD, Wiley J, Leveno KJ. Intensity of labor pain and cesarean delivery. Anesth Analg 2001; 92: 1524-8.

16. Collins SL, Moore RA, McQuay HJ. The visual analogue pain intensity scale: what is moderate pain in millimetres? Pain 1997; 72: 95-7.

17. Wallenstein SL. The measurement of pain. PRN Forum 1982; 1: 1-2, 5-6.

18. Barden TP, Stander RW. Effects of adrenergic blocking agents and catecholamines in human pregnancy. Am J Obstet Gynecol 1968; 102: $226-35$.

19. Wang F, Shen X, Guo X, Peng Y, Gu X. Epidural analgesia in the latent phase of labor and the risk of cesarean delivery: a five-year randomized controlled trial. Anesthesiology 2009; 111: 871-80.

20. Holmes P, Oppenheimer LW, Wen SW. The relationship between cervical dilatation at initial presentation in labour and subsequent intervention. BJOG 2001; 108: 1120-4. 